\title{
Marine 3D seismic volumes from 2D seismic survey with large streamer feathering
}

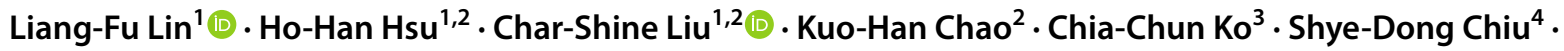 \\ Hsin-Sung Hsieh ${ }^{4} \cdot$ Yu-Fang $\mathrm{Ma}^{4}$. Song-Chuen $\mathrm{Chen}^{5}$
}

Received: 19 March 2019 / Accepted: 12 June 2019 / Published online: 22 June 2019

(c) The Author(s) 2019

\begin{abstract}
Strong ocean current influences a marine seismic survey and forces the streamer off-course from the survey line. The sideway drift of the streamer results in that the reflection data are no longer distributed in common midpoint gathers along the survey line but become swath distribution on one side of the ship track. This effect is known as "streamer feathering" which degrades the profile image of the 2D processed seismic data. However, if we have long streamer or closely spaced parallel 2D seismic survey lines, we may turn this deleterious effect into a good opportunity to generate 3D seismic volumes with swath distributed reflection data. We present two case studies in which 2D seismic data were collected offshore eastern Taiwan where the strong Kuroshio Current heavily influenced the ship speed and caused large streamer feathering. The first case is a large-offset 2D seismic profiling data collected using a 6-km long streamer. We processed the swath part of the reflection data in 3D that not only avoids the inappropriate smearing effect in $2 \mathrm{D}$ data processing but also generates a 3D seismic volume to help the seismic interpretation. In the second case, we adjusted our 2D survey strategy when realizing that strong Kuroshio Current was causing significant streamer feathering, and collected a set of closely spaced parallel 2D seismic lines. This multi-swath dataset covers a broad area which enables us to generate a 3D seismic volume. Since our datasets are not real 3D seismic data, we have tailored our processing flows to deal with different data configurations and limitations of each dataset. Our results show that not only we have enhanced 2D seismic images of the originally-interested survey lines, but also provide information on 3D geometry of the geological features imaged. The benefits and limitations of utilizing the streamer feathering effect to generate 3D seismic volumes from 2D seismic profile data are reported. Overall, this approach is a considerable way to handle 2D seismic data with large streamer feathering for both avoiding unreliable 2D seismic images and obtaining information on 3D geometry of the geological features imaged.
\end{abstract}

Keywords Multi-channel seismic data $\cdot 3 \mathrm{D}$ seismic volume $\cdot$ Streamer feathering $\cdot$ Seismic data processing

Char-Shine Liu

csliu@ntu.edu.tw

Liang-Fu Lin

marcus_lflin@outlook.com

Ho-Han Hsu

hhhsu@ntu.edu.tw

Kuo-Han Chao

fallen40@hotmail.com

Chia-Chun Ko

051641@cpc.com.tw

Shye-Dong Chiu

sdchiu@ntu.edu.tw

Hsin-Sung Hsieh

sisolshie@ntu.edu.tw
Yu-Fang Ma

mayufang@ntu.edu.tw

Song-Chuen Chen

songlin@moeacgs.gov.tw

1 Institute of Oceanography, National Taiwan University, No.1, Sec. 4, Roosevelt Road, Taipei 106, Taiwan

2 Ocean Center, National Taiwan University, No.1, Sec. 4, Roosevelt Road, Taipei 106, Taiwan

3 CPC Corporation, Miaoli, Taiwan

4 Marine Instrument Center, National Taiwan University, No.1, Sec. 4, Roosevelt Road, Taipei 106, Taiwan

5 Central Geological Survey, 2, Lane 109, Hua-Hsin Street, Chung-Ho, Taipei 235, Taiwan 


\section{Introduction}

Most geological features are 3-dimensional in nature. For better understanding the subsurface geometries of the geological complex, 3D seismic survey is an effective way. The 3D seismic technology is widely used in industrial hydrocarbon exploration for studying the relations between regional geology and hydrocarbon resources that reduces the risk and improves the success rate for exploration drilling (Alfaro et al. 2007). In general, industrial marine 3D seismic surveys are achieved by using multiple streamers (as many as 8-12 streamers) with single or multiple source arrays. However, conducting 3D seismic survey is prohibitively expensive for academic research, thus few educational and research institutions could keep up with the 3D revolution (Biondi 2006).

During a marine 2D survey, the streamer may not be straight along the survey line but deviated away due to wind, waves, and especially cross currents. This effect is called streamer feathering. The angle between ship track and streamer positions, called feathering angle, are less than $10^{\circ}$ in most cases (Yilmaz 2001). The sideway drift of the streamer configuration results in scattering of sourcereceiver midpoints and presents a swath distribution to one side of the ship track. In a typical 2D seismic data processing scheme, data traces are normally binned into common midpoint (CMP) gathers along a chosen straight line, generally the survey line, and the crossline offsets of the midpoints are often ignored during processing. This processing approach leads seismic signals which did not pass the subsurface strata of the profile to be summed into the subsurface image of the profile, and causes pitfalls on interpretation, including spurious discontinuities and wipeouts or blanking zones evident throughout the final profile image (Yilmaz 2001; Nedimovic et al. 2003). Once the streamer feathering angle becomes large, the degradation of the final 2D processed seismic profile image becomes apparent. It has always been difficult to conduct multichannel seismic survey in the area offshore eastern Taiwan where strong Kuroshio Current passing by (Fig. 1c). The speed of this ocean current is up to $5 \mathrm{~km} / \mathrm{h}$ to the east of Taiwan (Liang et al. 2003; Hsin et al. 2008) that strongly affects the ship speed and seismic streamer configuration. The feathering angle may deviate to more than $40^{\circ}$ which creates a relatively wide data swath, and this streamer feathering effect often degrades the $2 \mathrm{D}$ seismic profile images. As the actual reflection points collected by a large feathered streamer are distributed in a wide swath, we consider the dataset to be 3D in nature, and if we could process the dataset using 3D processing scheme and generate a 3D seismic volume following the actual reflection point distribution, we may turn the deleterious streamer feathering effect into a good opportunity for both understanding the 3D geometries of the geological features and avoiding the inappropriate 2D data binning.

In this study, 2 datasets from seismic surveys with a single source and a single multichannel streamer are used to test our idea. In the first case, we processed a strong feathered 2D large-offset seismic profile (a single swath) dataset in 3D point of view. We generated an elongate seismic image cube that not only improves $2 \mathrm{D}$ profile image but also provides information which help to better understand the $3 \mathrm{D}$ configurations of the substrata along this profile. In the second case, we tested 3D processing of a pseudo-3D dataset consisting of multiple parallel 2D seismic profile data with large streamer feathering angles (multi-swaths) that cover a wide area, and generated a 3D seismic image cube which reveals details of the geological features such as faults, volcanic intrusions and hydrothermal vents, etc., in the survey block. As these datasets are not true 3D seismic data, the processing feasibility is limited. We need to modify the processing flow based on the problems and limitations of the acquired datasets during 3D seismic data processing. The benefits, problems and limitations of this processing approach are presented.

\section{Case studies}

Two datasets are used in this study; both were collected in the area offshore eastern Taiwan where Kuroshio Current flows by. The seismic surveys were conducted to investigate the tectonics and crustal structures of the Ryukyu subduction-backarc extension system. In this area, the Philippine Sea Plate subducts northward beneath the Eurasia Plate to form the Ryukyu Subduction System (Fig. 1a). The Ryukyu subduction system in offshore eastern Taiwan consists of Ryukyu Trench, Yaeyama Ridge (accretionary wedge), Hoping, Nanao, and East Nanao Basins (forearc basins), Ryukyu arc, and Southern Okinawa Trough (SOT) backarc basin from south to north (Fig. 1b). Our 1st case is a single 2D seismic survey line running in NW-SE direction across the Hoping Basin collected by a $6-\mathrm{km}$ long streamer. The 2 nd case is a pseudo-3D seismic survey consists of a series of $\mathrm{N}-\mathrm{S}$ trending parallel 2D seismic lines in the rifting center of SOT. Since both surveys were conducted with survey lines running across the strong Kuroshio Current with high oblique angles, the strong ocean current caused large feathering angles on the streamers so that the source-receiver midpoints (reflection points) are scattered in a swath to one side of the survey lines. 3D processing of these two seismic datasets with large streamer feathering are presented below respectively for their regional geological backgrounds, data acquisition information, data processing flows, and results of the constructed 3D seismic cubes. 



Fig. 1 a Regional map around Taiwan. b Enlarged map shows regional structures and distribution of the datasets used in this study. c Shallow ocean current distribution map shows the strong Kuroshio Current flowing northward east of Taiwan (modified from Liang et al. 2003)

\section{Case 1: a single-swath dataset collected by a large offset seismic system}

\section{Geological background}

Hoping Basin is the westernmost forearc basin of the Ryukyu subduction system (Fig. 1b). Unlike other E-W trending forearc basins located farther away from Taiwan, Hoping Basin is strongly deformed and trends in NNW-SSE direction, indicating that this basin is located in an unstable junction area between Ryukyu Trench, Longitudinal Valley Fault, and the transform zone along which the Ryukyu Arc moves southward (Lallemand et al. 1997). Structural complex of strike slip faults and frequent earthquake activities are reported (e.g. Lallemand et al. 1997; Kao et al. 1998; Lallemand et al. 2001; Theunissen et al. 2012). Underlying the Hoping Basin sediments, thick Suao strata are observed that was suggested to be the sediments deposited in the old Suao Basin and later deformed and subsided with the interaction of subduction and collision processes in this area (Lallemand et al. 1997).

\section{Data acquisition}

A large-offset seismic profile (MGL0906-22N) which runs in NW-SE direction across the Hoping Basin (Fig. 2) is used here as the 1st case study. This dataset was acquired onboard R/V Marcus G. Langseth in 2009 under the scope of Taiwan Integrated Geodynamic Research (TAIGER) project. The streamer length is approximately $6 \mathrm{~km}$ with 468 channels spaced at $12.5 \mathrm{~m}$, and was towed at $9 \mathrm{~m}$ below sea surface. The source consists of a four-string-airgun array with a total volume of $6600 \mathrm{in}^{3}$ and towed at $8 \mathrm{~m}$ below sea surface. The shot interval is set at $50 \mathrm{~m}$ based on GPS positioning system. The record length is $15 \mathrm{~s}$ with $2 \mathrm{~ms}$ sampling rate. For each shot, a P1/90 file was built which records the coordinates of sources and all receiver channels, together with information on cable compasses, acoustic underwater distance 


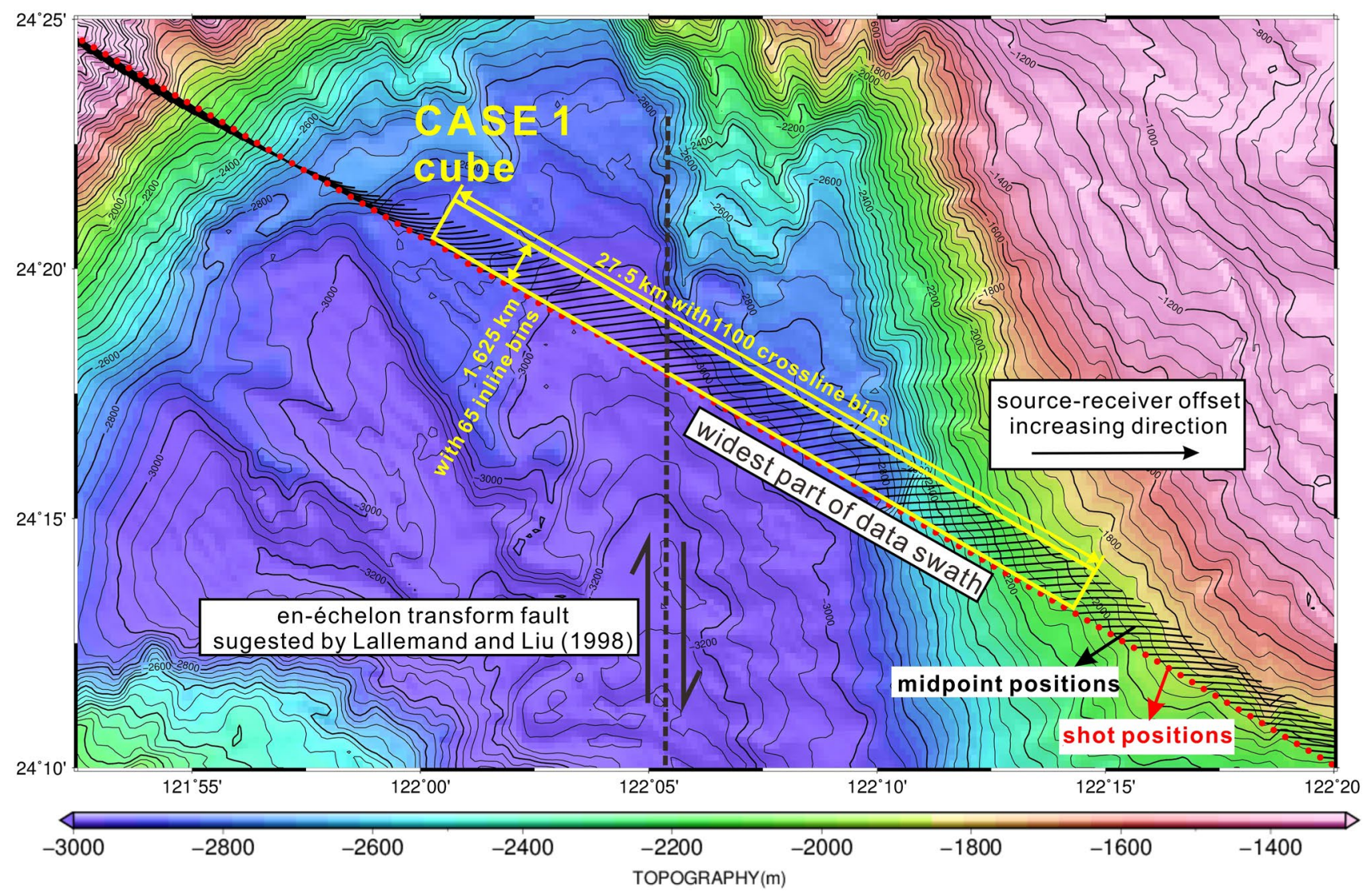

Fig. 2 Data distribution map of Case 1. Red dots and black dots present shot positions and source-receiver midpoints for every 10 shots. Yellow box shows the area coverage of the generated 3D seismic volume

Table 1 Seismic data acquisition parameters of the datasets used in this study

\begin{tabular}{lll}
\hline & Case 1 & Case 2 \\
\hline Dataset & MGL0906-22n & MCS1175-3D (19 2D lines) \\
R/V & Marcus G. Langseth & Ocean Researcher 1 \\
Streamer channel (maximum offset) & 468 Channels (6 km) & 120 Channels (1.65 km) \\
Recording length & $15 \mathrm{~s}$ & $6 \mathrm{~s}$ \\
Sampling rate & $2 \mathrm{~ms}$ & $1 \mathrm{~ms}$ \\
Channel interval & $12.5 \mathrm{~m}$ & $12.5 \mathrm{~m}$ \\
Source volume & $6600 \mathrm{in}^{3}$ & $415 \mathrm{in}^{3}$ \\
Shot interval (nominal) & $50 \mathrm{~m}$ & $25 \mathrm{~m}$ \\
R/V & Marcus G. Langseth & Ocean Researcher 1 \\
Streamer channel (maximum offset) & $468 \mathrm{Channels}(6 \mathrm{~km})$ & 120 Channels (1.65 km) \\
Recording length & $15 \mathrm{~s}$ & $6 \mathrm{~s}$ \\
Sampling rate & $2 \mathrm{~ms}$ & $1 \mathrm{~ms}$ \\
Channel interval & $12.5 \mathrm{~m}^{2}$ & $12.5 \mathrm{~m}$ \\
Source volume & $6600 \mathrm{in}^{3}$ & $415 \mathrm{in}^{3}$ \\
Shot interval (nominal) & $50 \mathrm{~m}$ & $25 \mathrm{~m}^{\circ}$ \\
\hline
\end{tabular}

measurements, and tailbouy positions. Table 1 summarizes the data acquisition parameters of this line.

MGL0906-22N ran across the three forearc basins, namely Eastern Nanao Basin, Nanao Basin, and Hoping
Basin from east to west (Fig. 1b). In the section over eastern part of the Hoping Basin, the streamer was strongly affected by the northward flowing Kuroshio Current, and rotated around $30^{\circ}$ anticlockwise. The source-receiver midpoints, 


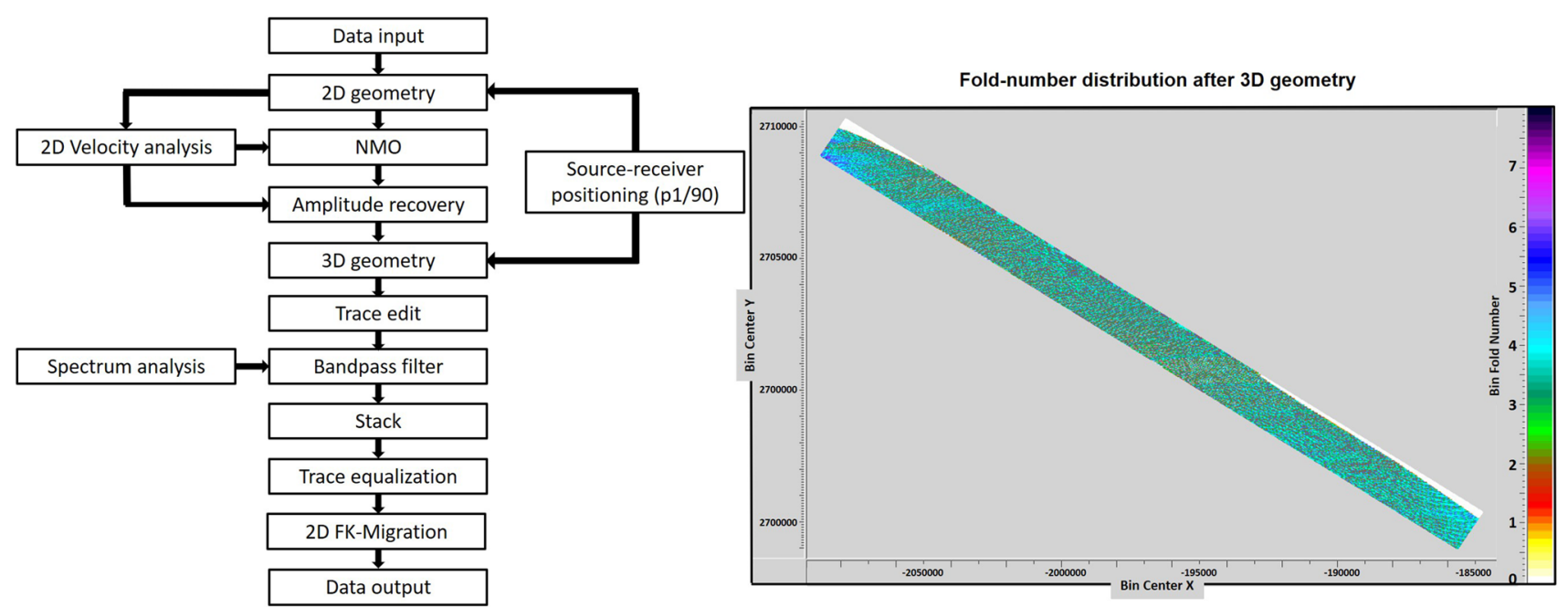

Fig. 3 Seismic data processing flow for Case 1 and the fold-number distribution map after 3D geometry

or the reflection points, thus were scattered in a swath on the eastern side of the ship track (Fig. 2). The width of the midpoint swath in this section is about $1650 \mathrm{~m}$, and those seismic data were selected to generate the 3D seismic data volume.

\section{Seismic data processing}

The basic seismic data processing procedures include geometry building, normal moveout correction (NMO), band-pass filtering, trace editing, amplitude correction, stack, and poststack migration (Fig. 3). Since a single swath data is not adequate to generate $3 \mathrm{D}$ velocity structures as reflection data with different offsets are separated in different CMP bins, we derive stacking velocity information from $2 \mathrm{D}$ velocity analyses and use these velocity values to perform NMO correction. In practice, we first performed standard 2D geometry based on recorded data acquisition configurations without taking streamer feathering into consideration. At this moment, data traces were binned to the CMP gathers along the survey line, then semblance velocity analyses were performed to obtain stacking velocities. NMO corrections and amplitude recovery were then performed based on these stacking velocities to establish a set of zero-offset traces for all the reflection traces.

Next, we build true 3D geometry of the reflection midpoints based on the actual shot and receiver locations. To set the grids of common-cell gathers (bins) of 3D geometry, the range, size, and numbers of bins in inline and crossline directions were carefully designed considering the actual midpoint distribution. To optimize the result, we try to strike a balance between increasing the resolution (smaller bin size) and reducing the number of 0 -fold (empty) bins (keep bin size large enough to have reflection point in the bin). For this study, we choose a bin size of $25 \mathrm{~m} \times 25 \mathrm{~m}$ and a rectangular area of $27.5 \mathrm{~km} \times 1.625 \mathrm{~km}$ to cover the scattered reflection midpoints. By doing so, we have 65 inline and 1100 crossline profiles for the 3D seismic volume constructed.

After the zero-offset seismic traces were allocated into their respective 3D geometry bins, bad traces were picked and removed, and a band pass filter was applied. Then, the zero-offset traces in each bin were stacked directly because NMO corrections had been applied already. After stacking, we employed trace equalization to reduce the inhomogeneous amplitude variations caused by irregular fold number distribution. Since we do not have 3D velocity information, we could not perform a full 3D migration. We tested two-pass migration (migrate the data in inline direction and crossline direction, respectively) with water velocity, but as the cross-line profiles are too short, the results were not good. In the end, we migrated the data only along inline direction for a better final result.

\section{Results of the constructed 3D seismic cube}

Looking through the elongated data cube, the lateral variations of geological features are apparent (Figs. 4, 5). The crossline and inline profiles show that the base of Hoping Basin dips southward, which reflects the underlying sedimentary strata of old Suao Basin have subsided to the south (Lallemand et al. 1997). In the western side of the 3D volume, vertically stacked submarine channels are identified below the modern channel. These channels have migrated slightly that can be observed on inline profiles (Fig. 5). High-angle faults are identified in the young Hoping Basin strata, their strikes and offsets can be observed on time slices (Fig. 4f), indicating that these faults are oriented in NE-SW 
(A)
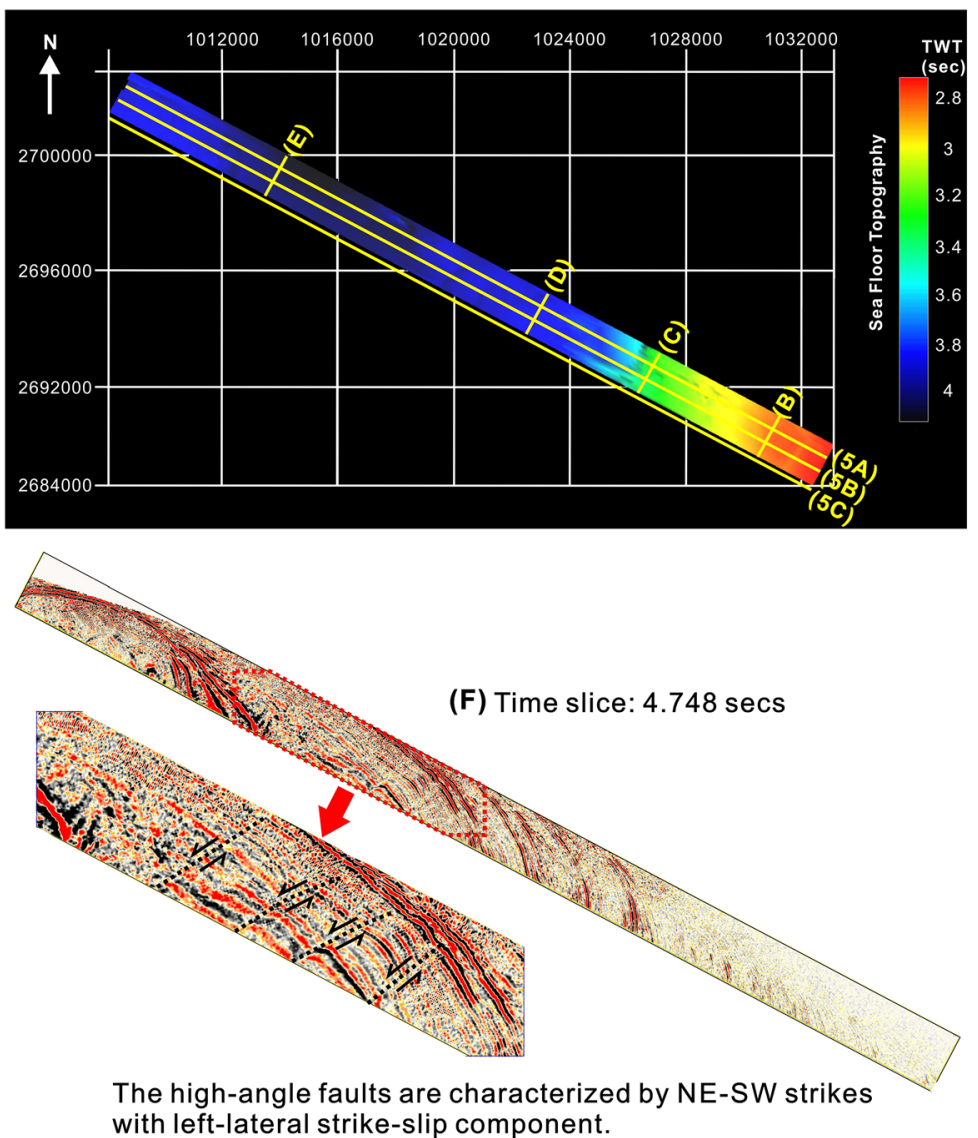

Distance (meter):

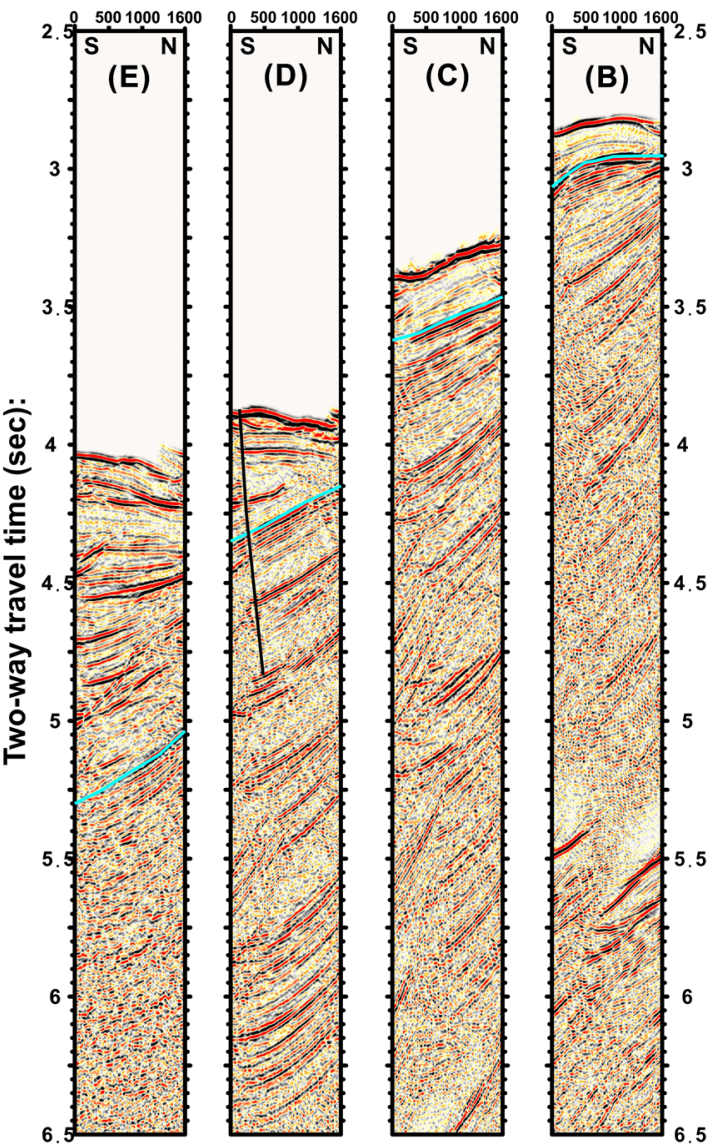

Fig. 4 Example of Case 1 results. a Colored stripe shows the area covered in 3D seismic volume. Different colors present seafloor topography in two-way traveltime. Yellow lines are the locations of the crossline and inline profiles shown in this figure and in Fig. 5,

direction, and their offsets have left-lateral strike-slip component. These observations reflect that the shear stress field of the Hoping Basin strata may be different from the geological model suggested by Lallemand and Liu (1998) (Fig. 2). Although the seismic volume is only a narrow stripe, the seismic images present distinct variation of geological features and the structural geometries in three dimensions. Comparing the inline seismic images (Fig. 5, b) with the F-K migrated 2D seismic section of the same dataset presented in Van Avendonk et al. (2015) (Fig. 5c). Though the deep reflections appear stronger in the $2 \mathrm{D}$ processed seismic profile image, many details in the upper part of the section are not clear (Fig. 5c). For example, the stratigraphic terminations and fault structures observed on the inline sections (Fig. 5a, b) are not identified in Fig. 5c, and many trans- parent patches appeared in Fig. 5c may be caused by crossline smearing due to large streamer feathering. Our new observations from the 3D seismic image volume help to reveal the 3D geometry of geological features and avoid respectively. $\mathbf{b}-\mathbf{e}$ Crossline profiles and $\mathbf{f}$ a time slice reveals lateral structural variations and quality of the constructed 3D seismic volume. Red box indicates the location of the enlarged time slice which shows fault structures

many pitfalls on 2D processing of a single seismic profile with large streamer feathering.

\section{Case 2: a multi-swath dataset in the Southern Okinawa Trough}

\section{Geological background}

The Southern Okinawa Trough (SOT) located offshore northeastern Taiwan is a backarc basin behind the Ryukyu arc where rifted crustal structures, magmatic and hydrothermal activities are widely observed (Sibuet et al. 1998; Lin et al. 2007; Shyu and Liu 2001; Klingelhoefer et al. 2009; Gena et al. 2013). In 2017, a seismic survey was carried out to investigate the $\mathrm{E}-\mathrm{W}$ trending central rift zone of SOT. The N-S running seismic lines which were designed to go perpendicularly to the structural trend are in high oblique angle with the ENE flowing Kuroshio Current in the survey area. As the streamer feathering became large, we decided 
Fig. 5 a, b Inline profiles of Case 1 show the quality of constructed $3 \mathrm{D}$ seismic volume in inline direction. In comparison to inline profiles from the $3 \mathrm{D}$ cube, $\mathbf{c} 2 \mathrm{D}$ processed $\mathrm{F}-\mathrm{K}$ migrated seismic image of the same section in Hoping Basin east of Taiwan (modified from Van Avendonk et al. 2015)




Fig. 6 Data distribution map of Case 2. Red dots and black dots present the shot positions and the source-receiver midpoints at every 10 shots. Yellow box indicates the area covered by the 3D seismic volume

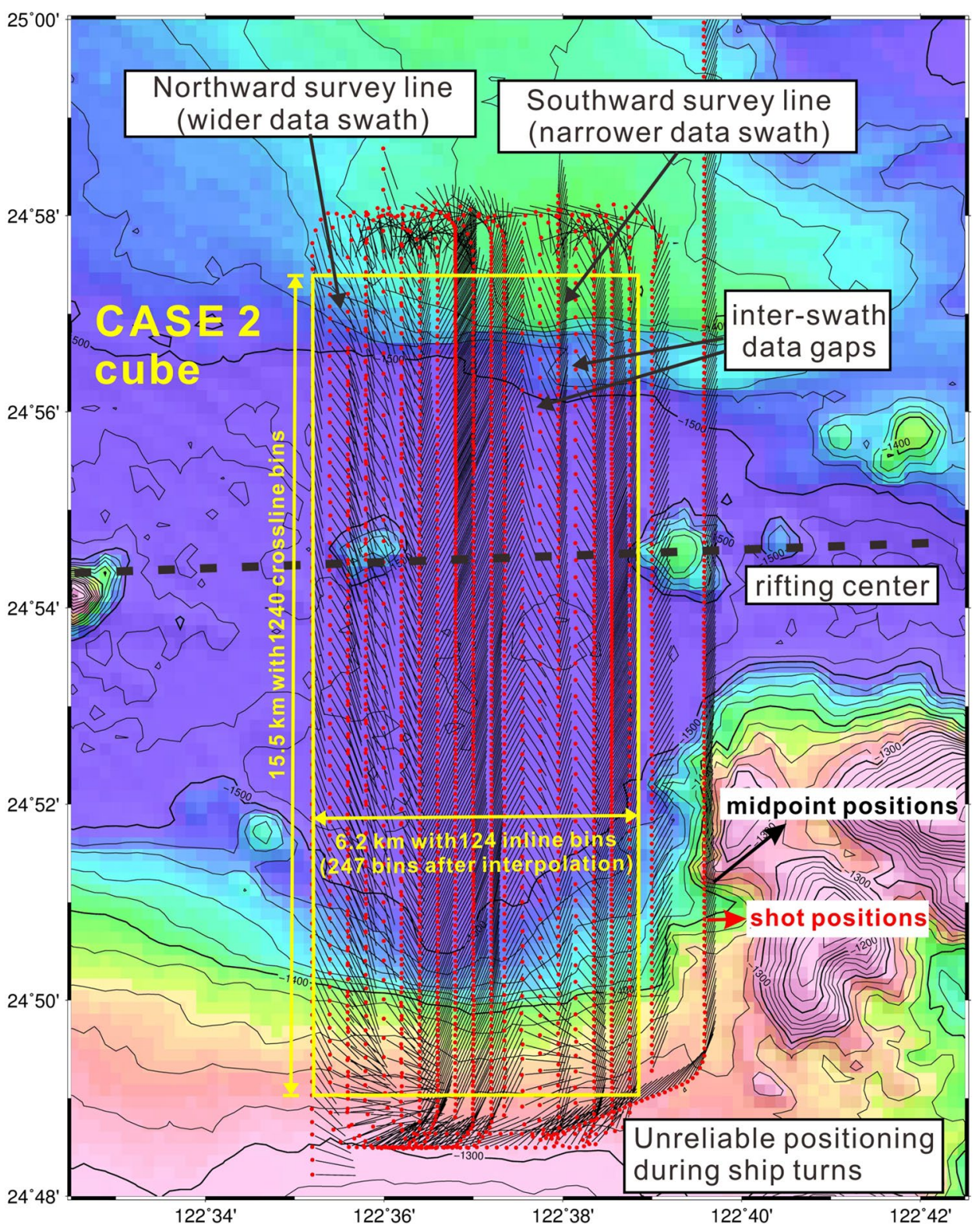

to reduce the originally designed $2 \mathrm{D}$ survey lines to conduct a pseudo-3D seismic survey. This approach provides us the opportunity to generate a 3D seismic image block from our 2D seismic data acquisition system onboard R/V Ocean Researcher 1.

\section{Data acquisition}

The dataset used for this case consists of 19 densely spaced 2D seismic lines in the rifting center of SOT (Fig. 6). The survey lines are spaced about $350 \mathrm{~m}$, and the seismic data were collected using a $1.65 \mathrm{~km}$ long 120-channel streamer with $12.5 \mathrm{~m}$ channel interval. The source used is a string of 3-airgun array with 415 in $^{3}$ in total volume. Both streamer and airgun array were towed at $5 \mathrm{~m}$ below sea surface. The shot interval is set at $10 \mathrm{~s}$, or about $25 \mathrm{~m}$ for ship speed at 4.86 knots $(2.5 \mathrm{~m} / \mathrm{s})$. But as the seismic lines are in $\mathrm{N}-\mathrm{S}$ direction, the ship speed was strongly influenced by the Kuroshio Current, and the shot intervals are less than $25 \mathrm{~m}$ in southward survey lines (slower ship speed) while the shot distances are larger than $25 \mathrm{~m}$ in northward survey lines (faster ship speed) (Fig. 6). The record length is $6 \mathrm{~s}$ with $1 \mathrm{~ms}$ sampling rate. Table 1 summarizes the data acquisition parameters.

The 120-channel seismic data acquisition system does not have sophisticated navigation system; the calculations of acquisition configuration for each shot are thus simplified. The source positions are calculated based on a fixed lay back distance from the GPS antenna in the middle of the ship, and the positions of the receivers for each shot are calculated 


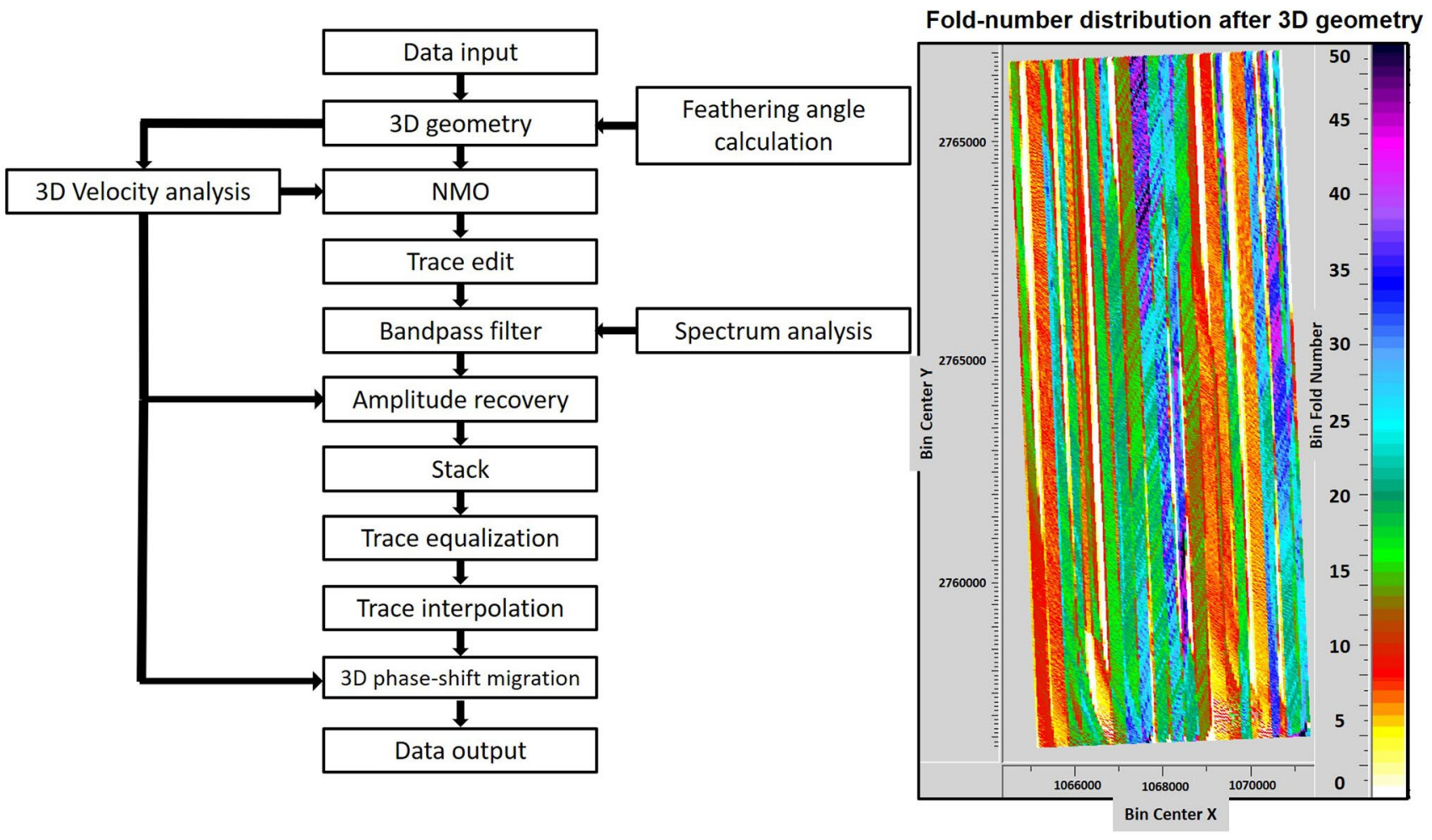

Fig. 7 Seismic data processing flow for Case 2 (left) and the fold-number distribution map after 3D geometry (right). Cold colors indicate where high-fold bins are distributed

based on the near-offset from source position, channel interval, the GPS positions on tailbuoy, and streamer featuring angle. The 120-channel streamer is generally straight during surveying, confirmed by the compass headings in the streamer depth control units and by the computed distance between the ship and the tailbuoy GPSs, except when ship turns.

During our survey, the streamer feathered by around $20^{\circ}-40^{\circ}$ depending on the current strength and surveying direction, large feathering in northward survey lines and small feathering in southward survey lines (Fig. 6). The source-receiver midpoints are scattered in a swath distributed on the east side of the survey lines, and the widths of midpoint swaths range from 280 to $530 \mathrm{~m}$. With a nominal line spacing of $350 \mathrm{~m}$, the midpoint swaths often overlap each other and the reflection midpoints cover most of the survey area, but in some places there are gaps between midpoint swaths and formed holes in the 3D distribution of reflection midpoints (Figs. 6, 7).

\section{Seismic data processing}

For this dataset, as they were collected using pseudo-3D seismic data acquisition approach, the distribution of reflection midpoints covers a large area, we processed this dataset following standard $3 \mathrm{D}$ seismic data processing procedures
(Fig. 7). First, we set the 3D geometry after choosing a proper bin size. The range, size, and numbers of bins in inline and crossline directions all need to be considered based on the actual midpoint distribution to provide a high resolution reflection grid with less 0 -fold (empty) bins. We decided to set the bin size to be $50 \mathrm{~m} \times 12.5 \mathrm{~m}$ as we have much larger cross-line spacing than inline spacing. We chose a rectangular grid covers an area of $15.5 \mathrm{~km} \times 6.2 \mathrm{~km}$, i.e. 124 inlines and 1240 crosslines. After traces were allocated into their respective $3 \mathrm{D}$ bins, $3 \mathrm{D}$ velocity analyses were performed on supergathers at every 6 inline bins by 100 crossline bins. As the data are irregularly distributed, supergathers for velocity analysis are designed to combine 7 inline bins and 11 crossline bins. The final velocity model consists of 240 velocity control nodes in the $96.1 \mathrm{~km}^{2}$ area. NMO corrections were performed with those velocity results. Before stacking, bad traces had been picked and removed and bandpass filter applied, then traces in each bin were stacked and trace equalization was applied to reduce the inhomogeneous amplitude distribution led by irregular fold number distribution. As the resolution in crossline direction $(50 \mathrm{~m})$ may result in spatial aliasing on migration, we interpolated the poststack traces in crossline direction that not only fills the 0 -fold bins but also doubles the inline numbers (from 124 to 247 inlines). 3D phase-shift migration method was selected to construct a migrated data volume with less 
spatial aliasing effect (Yilmaz 2001). Migration of the 3D seismic data volume was performed using our 3D velocity information.

\section{Results of the constructed 3D seismic cube}

The 3D seismic image cube constructed in this case reveals extensional tectonic features in SOT central rift zone very well (Figs. 8, 9, and 10). Crossline images, though somewhat short on length $(6.2 \mathrm{~km})$, can provide clear images on lateral variations of the geological features imaged (Fig. 8). Inline profiles which run across the regional structures reveal conjugate normal faults and tilted blocks clearly on both sides of the SOT central rift zone (Fig. 9). The geometries of extruded volcanos in the central rift zone can be defined in the images from all three dimensions (Figs. 8, 9). Around the volcanos and faults, high amplitude reflections and acoustic blanking zones are observed. The high amplitude events are interpreted as the igneous sills related to nearby magmatic intrusion or extrusion. The acoustic blanking zones are interpreted as fluid-related features which can be corresponding to a hydrothermal venting site, named GLM, where gas plumes are observed in water column acoustic images (Fig. 9b). All the features outline the hydrothermal system in this rifting area. More geological interpretations from this dataset are presented by Hsu et al. (2019).

Seismic attribute analyses have been performed to enhance the 3D images of some specific geological features that can be displayed on top view or perspective view (Fig. 10). The distributions of normal faults, strong reflections surrounding the volcanos and the fluid-related blanking zones can be easily observed on the time slices (Fig. 10). This case study demonstrates the advantage of having a 3D seismic volume on studying the geometries and relations between the faulted blocks, volcanic extrusions, and hydrothermal vents in this part of SOT.

\section{Discussion}

\section{Benefits}

Our two case studies demonstrate the benefits of turning large feathered 2D seismic datasets into 3D seismic volumes. After 3D geometry process with rigorously-calculated source-receiver midpoint locations and carefully designed binning grids, the seismic signals are allocated to the processing bins where they actually should be. This step reduces the distances between the processing bins and the actual reflection point locations, and keeps the seismic signals representing the subsurface at their actual locations. In addition, we have images from all three dimensions to reveal the lateral variations of geological features. In the first case, we turn a 2D seismic profile into an elongated seismic cube. Observations can be made not just on a single 2D profile with many pitfalls. Once seeing the relief of the base of Hoping Basin and the structural features in the third dimensions, we realize that we should not just to stack lateral variations into a 2D profile. In the second case, we turn $192 \mathrm{D}$ seismic profile data into a 3D seismic volume with 124 inline profiles after 3D seismic data processing. This approach increases the lateral resolution by about 6 times. Poststack trace interpolation helps not only reducing the aliasing on migration, but also increases the number of crossline bins by two folds on the final result. Therefore, we cannot have seismic images on all three dimensions to see the real geometries of geological features. The time slice images created are effective to present features on map view that intuitively displaying the spatial information like structural strikes and horizontal offsets of the faults.

Additional benefits include that 3D seismic attribute analyses using multiple traces can be applied on these data volumes (Fig. 10). The seismic attributes highlight geological or geophysical events. Combining these techniques, the seismic expression of faults and stratigraphic features can be revealed even clearer. In our study, we have tried some edge detection attributes to highlight faults and some reflection strength attributes for identifying structures. The results are helpful for interpreters to see their targets effectively.

\section{Limitations and problems}

Since the datasets are acquired by $2 \mathrm{D}$ seismic systems, there are limitations and problems that need to be carefully considered during 3D seismic data processing.

The positioning of source and receiver should be as accurate as possible. Misplaced reflection signals will not create reliable 3D seismic images. For example, seismic data acquired during the ship turns should be removed if the positioning method cannot accurately calculate the positions of sources and receivers.

Insufficient number of traces and lack of uniformity on fold coverage are the major limitations for generating a 3D volume by using $2 \mathrm{D}$ dataset. In our cases, the streamers cannot be controlled manually, the degree of streamer feathering depends on in situ ocean current and ship heading and speed so that the width of the midpoint distribution varies, and there could be some no-data areas and high data density areas (Figs. 6, 7). After 3D binning, 0-fold bins become holes in seismic images. These gaps or holes can be filled by trace interpolation methods or just by migration methods if the gaps are not too large. In addition, trace amplitude after stack may be influenced by irregular fold distribution. If so, trace equalization should be applied for standardizing the amplitude before migration. 
Fig. 8 Example of Case 2 results. a Colored box shows the area covered by $3 \mathrm{D}$ seismic volume. Different colors present seafloor topography in two-way travel time. Yellow lines show the locations of crosslines and inlines shown in this figure and in Fig. 9, respectively. White dash line marks the location of the rift center. $\mathbf{b}-\mathbf{d}$ crossline profiles and $\mathbf{e}, \mathbf{f}$ time slices showing the quality of constructed 3D seismic volume and the complex structures
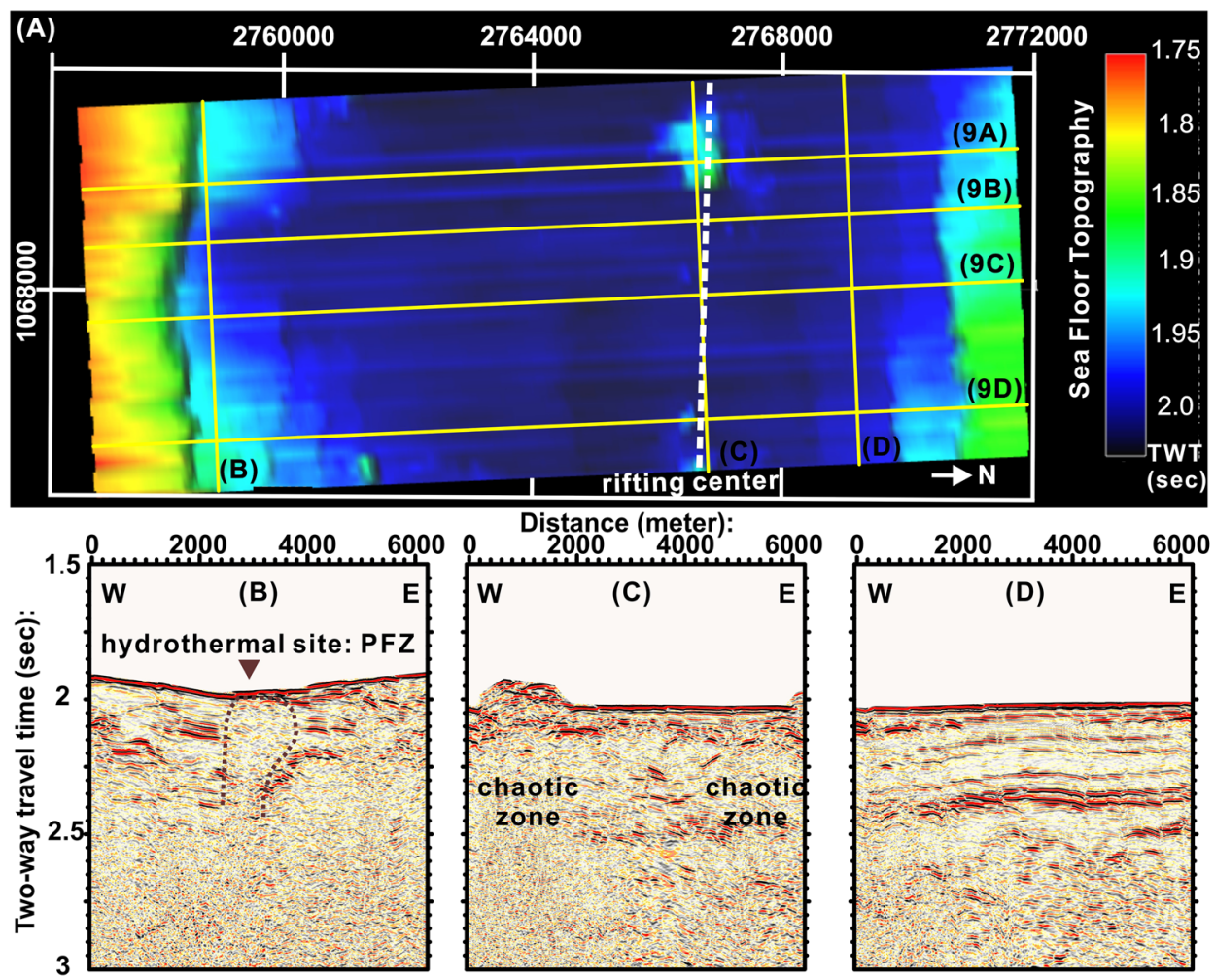

(E) Time slice: 2.080 secs



(F) Time slice: 2.164 secs

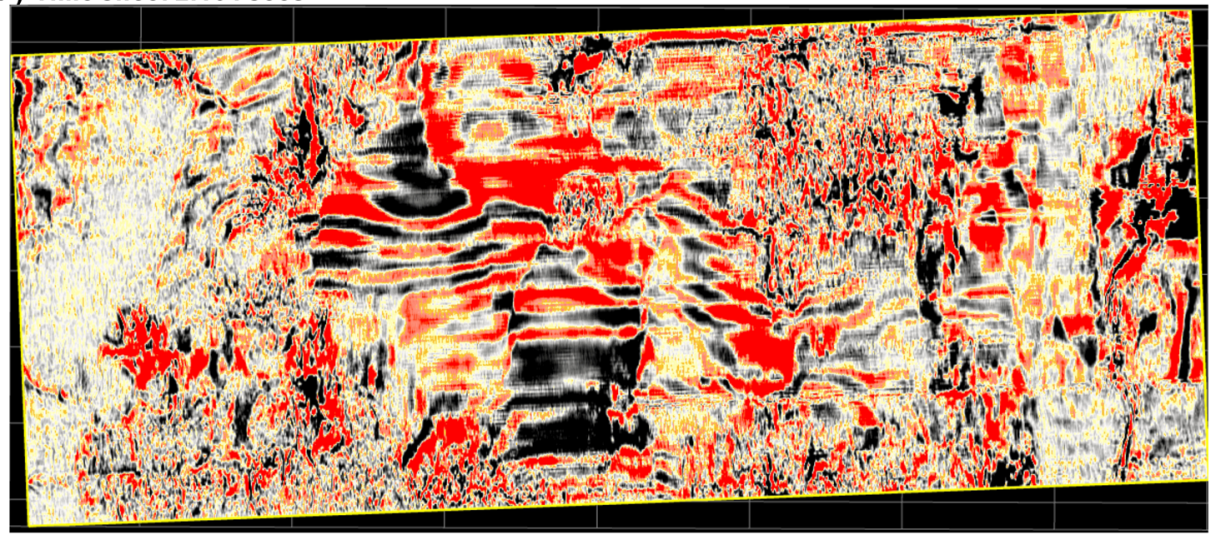


Fig. 9 a-d Inline profiles of Case 2 showing the quality of constructed 3D seismic volume in inline direction


Problems on range limited traces in 3D bins and lack of uniformity in the fold of coverage. When composing 3D bins from 2D reflection midpoints of different shots, some inline profiles may contain mainly near-offset traces while other inline profiles present mainly far-offset traces (Figs. 2,
6). We have analyzed the power spectrum on traces from different channels of the long streamer used in case 1 . Their spectra indicate that the high-frequency signals $(>100 \mathrm{~Hz})$ are attenuated as the offset increases (Fig. 11). Although we may not be able to differentiate near-offset profiles from 
Fig. 10 Attribute analyses on the 3D seismic volume of Case 2 showing the enhanced geological features on time slice images. The selected time slice is displayed with different attributes: a amplitude, b RMS amplitude, and $\mathbf{c}$ variance
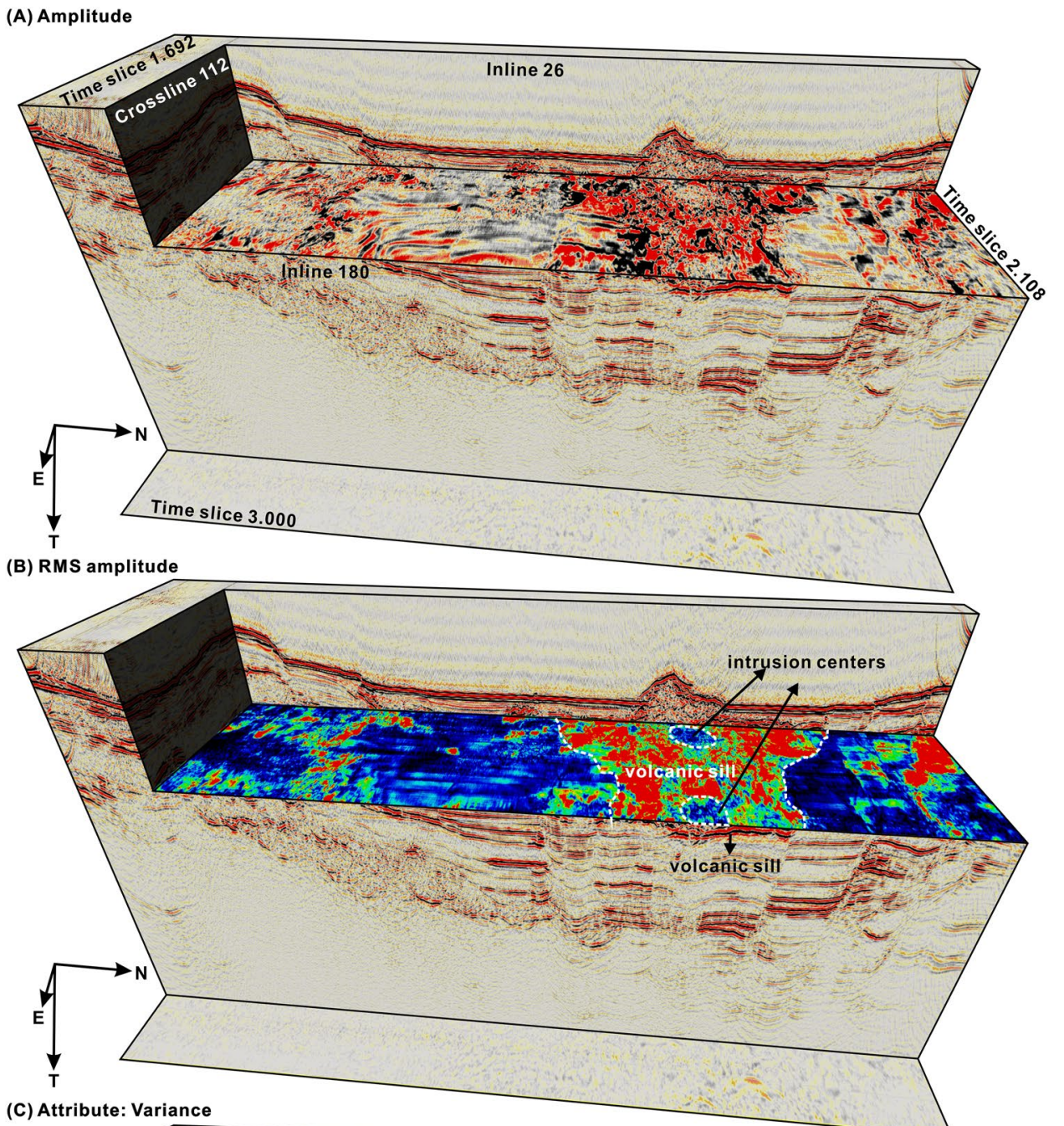

(C) Attribute: Variance

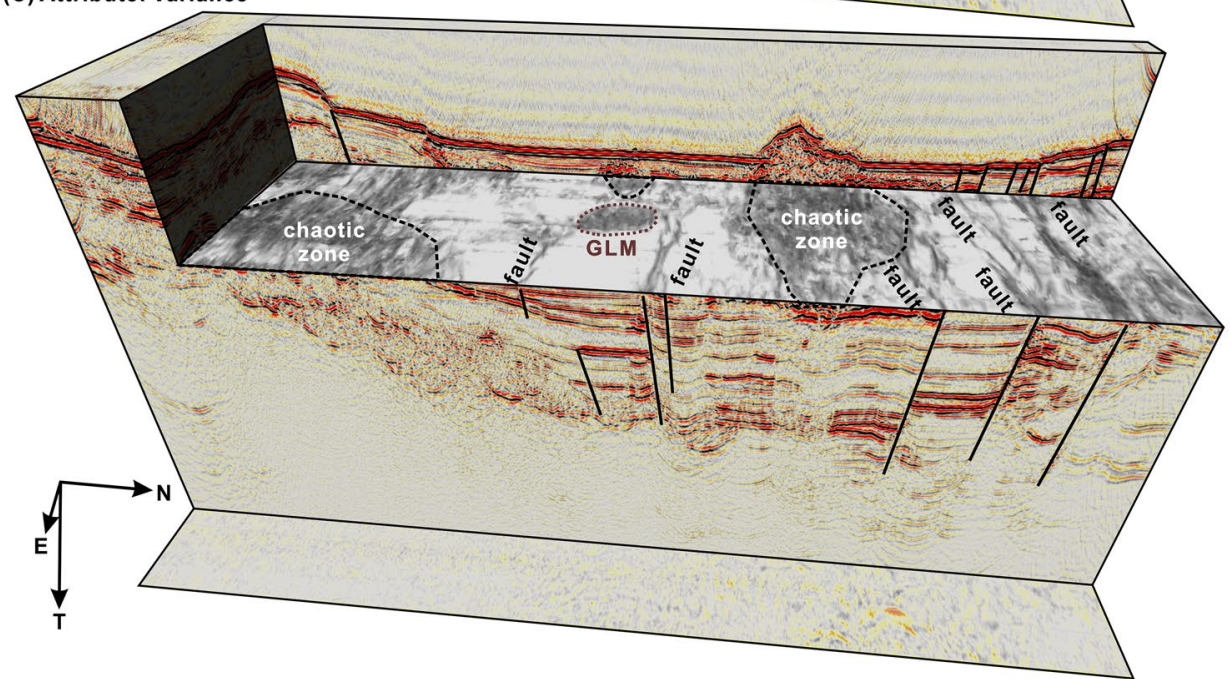

Another limitation is that velocity analysis cannot be performed on range limited data. In our first case, we could analyze the $3 \mathrm{D}$ velocity structure from the single swath dataset by using near-offset traces for near-offset area and far-offset traces for far-offset area, but the results would not far-offset profiles without direct comparison, the loss of vertical resolution on far-offset profiles will influence our interpretation, and the differences on frequency contents may affect the applications of some processes on crossline or three-dimensional processing. 


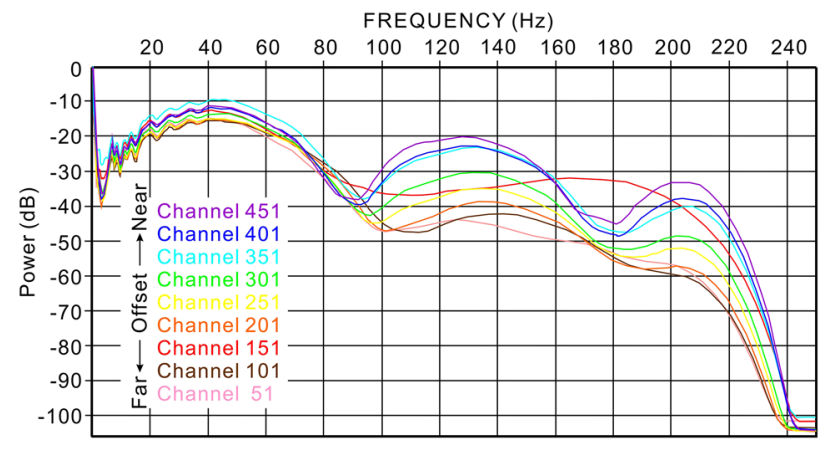

Fig. 11 Spectrum analysis of selected channels at different offsets from Case 1 dataset. The result shows that high frequency signals are attenuated in far offset traces

be reliable, so we chose to apply NMO correction with the results from $2 \mathrm{D}$ velocity analysis. In the second case, we performed 3D velocity analysis on constructed supergathers which may contain far-offset traces from one midpoint swath and near-offset traces from the next swath in many places.

The size of the binning grid for 3D geometry defines the resolution of the seismic cube and final images. Depending on the distribution of reflection midpoints, we may need to choose a larger bin size in crossline direction to reduce the number of 0 -fold bins. This choice concurrently reduces lateral resolution of poststack volume and also creates aliasing problems when doing migration due to the large poststack trace interval. The applications of trace interpolation or choosing a proper migration method may help to improve the images.

\section{Conclusions}

After our two case studies, the streamer feathering seems no longer to be just a deleterious effect that makes 2D seismic processing inappropriate and profile images unreliable. In this paper, both benefits and problems on converting 2D seismic data with large streamer feathering into 3D seismic volume are presented. Constructing 3D seismic volume with data acquired by $2 \mathrm{D}$ system is beneficial on academic research, as we may view the imaged geological features from 3D perspectives and also reducing the pitfalls caused by conventional 2D data binning on large streamer feathered data. However, there are problems and limitations on applying this approach. Comparing to a conventionally processed 2D seismic profile, the 3D seismic block provides continuous inline profiles, crossline profiles and horizontal slices which help to reveal additionally information on spatial variations of the geological structures imaged. The lateral variation of geological features observed in our case studies also shows how careful we should be when binning the feathered
2D data, especially in areas where strong cross-track ocean current presents. However, limitations for this approach are experienced during 3D data processing in our studies. Fine and accurate positioning of source and receiver is a fundamental requirement for this approach. The insufficient trace numbers and inhomogeneous distribution of reflection midpoints are major limitations when generating a 3D seismic volume using 2D seismic dataset. This limitation leads to many extended problems, for example, the traces from different offsets with different dominate frequency bands and amplitude ranges are irregularly distributed. These limitations need to be dealt carefully to avoid problems on 3D seismic data processing.

Acknowledgements We would like to thank the Central Geologic Survey, Ministry of Economic Affairs and the National Science Council (now the Ministry of Science and Technology), ROC for their supports to the projects in which the datasets analyzed in this paper were collected. The captains, crew and technical and scientific personnel onboard the R/Vs Ocean Researcher I and Marcus G. Langseth are appreciated for their efforts in collecting the seismic data used in this study. We also thank former members of Seismic Exploration Laboratory in Institute of Oceanography, National Taiwan University for developing the seismic data processing system and techniques. The comments and suggestions from the reviewers help to improve the quality of this paper. Financial supports of this study are from Central Geologic Survey (106-5226904000-05-01; 107-5226904000-05-01) and Ministry of Science and Technology (NSC-98-2611-M-002-007).

Open Access This article is distributed under the terms of the Creative Commons Attribution 4.0 International License (http://creativeco mmons.org/licenses/by/4.0/), which permits unrestricted use, distribution, and reproduction in any medium, provided you give appropriate credit to the original author(s) and the source, provide a link to the Creative Commons license, and indicate if changes were made.

\section{References}

Alfaro JC, Corcoran C, Davies K, Pineda FG, Hampson G, Hill D, Howard M, Kapoor J, Moldoveanu N, Kragh E (2007) Reducing exploration risk. Oilfield Rev 19(1):26-43

Biondi BL (2006) 3D seismic imaging. Society of Exploration Geophysicists, Tulsa. https://doi.org/10.1190/1.9781560801689

Font Y, Liu CS, Schnurle P, Lallemand S (2001) Constraints on backstop geometry of the southwest Ryukyu subduction based on reflection seismic data. Tectonophysics 333(1-2):135-158. https ://doi.org/10.1016/S0040-1951(00)00272-9

Gena K, Chiba H, Kase K, Nakashima K, Ishiyama D (2013) The Tiger Sulfide Chimney, Yonaguni Knoll IV Hydrothermal Field, Southern Okinawa Trough, Japan: the First Reported Occurrence of Pt$\mathrm{Cu}-\mathrm{Fe}-$ Bearing Bismuthinite and Sn-Bearing Chalcopyrite in an Active Seafloor Hydrothermal System. Resour Geol 63:360-370. https://doi.org/10.1111/rge.12015

Hsin YC, Wu CR, Shaw PT (2008) Spatial and temporal variations of the Kuroshio east of Taiwan, 1982-2005: a numerical study. J Geophys Res. https://doi.org/10.1029/2007JC004485

Hsu HH, Lin LF, Liu CS, Chang JH, Liao WZ, Chen TT, Chao KH, Lin SL, Hsieh HS, Chen SC (2019) Pseudo-3D seismic imaging of Geolin Mounds hydrothermal field in the Southern Okinawa Trough offshore NE Taiwan. Terr Atmos Ocean Sci (accepted) 
Kao H, Shen SSJ, Ma KF (1998) Transition from oblique subduction to collision: earthquakes in the southernmost Ryukyu arcTaiwan region. J Geophys Res 103(B4):7211-7229. https://doi. org/10.1029/97JB03510

Klingelhoefer F, Lee CS, Lin JY, Sibuet JC (2009) Structure of the southern-most Okinawa Trough from reflection and wide-angle seismic data. Tectonophysics 466(3-4):281-288. https://doi. org/10.1016/j.tecto.2007.11.031

Lallemand S, Liu CS (1998) Geodynamic implications of presentday kinematics in the southern Ryukyu. J Geol Soc China 41:551-564

Lallemand S, Liu CS, Font Y (1997) A tear fault boundary between the Taiwan orogen and the Ryukyu subduction zone. Tectonophysics 274(1-3):171-190. https://doi.org/10.1016/S0040-1951(96)00303 $-4$

Lallemand S, Font Y, Bijwaard H, Kao H (2001) New insights on 3-D plates interaction near Taiwan from tomography and tectonic implications. Tectonophysics 335(3-4):229-253. https://doi. org/10.1016/S0040-1951(01)00071-3

Liang WD, Tang TY, Yang YJ, Ko MT, Chuang WS (2003) Upperocean currents around Taiwan. Deep Sea Res Part II 50(67):1085-1105. https://doi.org/10.1016/S0967-0645(03)00011-0

Lin JY, Sibuet JC, Lee CS, Hsu SK, Klingelhoefer F (2007) Origin of the southern Okinawa Trough volcanism from detailed seismic tomography. J Geophys Res. https://doi.org/10.1029/2006J B004703

Nedimović MR, Mazzotti SH, Hyndman RD (2003) Three-dimensional structure from feathered two-dimensional marine seismic reflection data: the eastern Nankai Trough. J Geophys Res. https ://doi.org/10.1029/2002JB001959

Shyu CT, Liu CS (2001) Heat flow of the southwestern end of the Okinawa Trough. Terr Atmos Ocean Sci 12(2-1):305. https://doi. org/10.3319/TAO.2001.12.S.305(ODP)

Sibuet JC, Deffontaines B, Hsu SK, Thareau N, Formal JPL, Liu CS (1998) Okinawa trough backarc basin: early tectonic and magmatic evolution. J Geophy Res 103(B12):30245-30267. https:// doi.org/10.1029/98JB01823

Theunissen T, Lallemand S, Font Y, Gautier S, Lee CS, Liang WT, Wu F, Berthet T (2012) Crustal deformation at the southernmost part of the Ryukyu subduction (East Taiwan) as revealed by new marine seismic experiments. Tectonophysics 578:10-30. https:// doi.org/10.1016/j.tecto.2012.04.011

Van Avendonk HJ, McIntosh KD, Kuo-Chen H, Lavier LL, Okaya DA, Wu FT, Wang CY, Lee CS, Liu CS (2015) A lithospheric profile across northern Taiwan: from arc-continent collision to extension. Geophys J Int 204(1):331-346. https://doi.org/10.1093/gji/ggv468

Yilmaz Ö (2001) Seismic data analysis: processing, inversion, and interpretation of seismic data. Society of Exploration Geophysicists, Tulsa. https://doi.org/10.1190/1.9781560801580

Publisher's Note Springer Nature remains neutral with regard to jurisdictional claims in published maps and institutional affiliations. 